\title{
Bioactive Properties of Spirulina: A Review
}

\author{
Amir Ali Anvara, Bahareh Nowruzib*
}

Abstract

Spirulina is a single-cell protein rich in all essential nutrients and vitamins and can be used to produce functional food. In fact, one of the most important problems in the food industry is the use of synthetic food additives that increase the risk of cancer. Therefore, efforts are being made around the world today to isolate new and safe antioxidants from natural sources. Among these, the natural products of cyanobacteria are an important source of new drug compounds. Natural bioactive products not only have medicinal value themselves but are also used as building models to create synthetic analogs. The chemical composition of Spirulina includes protein (70-55\%), carbohydrates (25-25\%), essential fatty acids (18\%), vitamins, minerals, and pigments such as carotene, chlorophyll $A$ and phycocyanin. Obviously, the introduction of valuable properties of cyanobacteria Spirulina can be a suitable substitute for many antimicrobial compounds and synthetic antioxidants that not only pose no risk to the consumer but can also improve consumer health. In this review, we have discussed the important nutrient, bioactive properties, and immunological applications of Spirulina. The current research suggests that spirulina supplementations have been accepted by global accreditation as a safe nutritional and dietary supplement.

\section{Significance | Role of Spirulina as important dietary supplements}

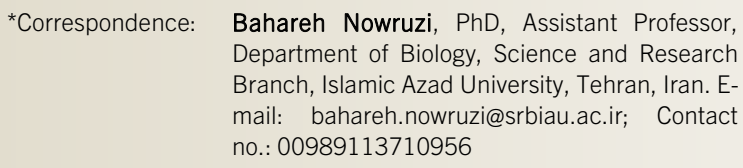
Department of Biology, Science and Research Branch, Islamic Azad University, Tehran, Iran. Email: bahareh.nowruzi@srbiau.ac.ir; Contact no.: 00989113710956

Edited by Md. Asaduzzaman Shishir, PhD, Editors at Eman Research Ltd, 10-14 Wormald Street, Symonston, Canberra, ACT 2609 Australia, and accepted by the Editorial Board May 11, 2021 (Received for review February 7, 2021)
Keywords: Dietary supplements; Food; Safe nutrition; Spirulina.

Abbreviations: HCC, Hepatocellular carcinoma cells; $\mathrm{MCH}$, Mean capsular hemoglobin; MCV, Mean corpuscular volume; MCHC, Mean corpuscular hemoglobin concentration; FAO, Food and Agriculture Organization; WHO, World Health Organization; NPU, Net protein utilization; LPL, Lipoprotein lipase; RDA, Recommended Dietary Allowance; 6-OHDA, 6hydroxydopamine; HCC, Hepatocellular carcinoma cells; DMBA, 7,12 dimethylbenz(a)-anthracene; C-PC, C-phycocyanin; Se-PC, Seleniumcontaining phycocyanin; HSC, Hepatic stellate cell.

\section{Introduction}

Spirulina is a cyanobacteria genus that has achieved the ability to utilize carbon dioxide dissolved in seawater as a nutrient source for their reproduction (Ali \& Saleh, 2012). The genus Spirulina of the Oscillatoriaceae family consists of filamentous cyanobacteria characterized by straight-shaped chains of cells enclosed in a thin sheath (Fig. 1). It is a photosynthesizing cyanophyte that grows vigorously in strong sunshine under high temperatures and highly alkaline conditions. Spirulina are filamentous cyanobacteria that have achieved significant approval in the health food industry and progressively as a protein and vitamin supplement to aquaculture diets. It grows in salt water and fresh water and can be harvested and processed easily and has very high macro- and micronutrient contents (Costa et al., 2019; Rosario \& Josephine, 2015; Soni, Sudhakar, \& Rana, 2017; Wan, Wu, \& Kuča, 2016).

It is possible to cultivate Spirulina with different systems, photobioreactors and raceways are a couple of the most known technologies. Raceways are generally rectangle with rounded corners and need a ground space, a lot of water and are dependent on weather and seasons. Photobioreactors are closed cultivation systems and therefore protect Spirulina strains from any external contamination. Cultivation parameters such as $\mathrm{pH}$, temperature or light could be controlled easily in these systems (Wan et al., 2016).

\footnotetext{
Author Affiliation:

a Department of Food Hygiene, Science and Research Branch, Islamic Azad University, Tehran, Iran.

${ }^{b}$ Department of Biology, Science and Research Branch, Islamic Azad University, Tehran, Iran.

Please cite this article:

Anvar AA and Nowruzi B (2021). Bioactive Properties of Spirulina: A Review. Microbial Bioactives, 4( 1), 134-142.

2209-2153/@ 2018 MICROBIAL BIOACTIVES, a publication of Eman Research Ltd, Australia. This is an open access article under the CC BY-NC-ND license. (http://creativecommons.org/licenses/by-nc-nd/4.0/) (http://microbialbioactives.emanresearch.org).
} 
It has long been used as a dietary complement by people living close to the lakes where it is naturally found (Ali \& Saleh, 2012). For example, Dihé is an outmoded food which is cultured worldwide. Especially, in many countries of Africa, Dihé collected from alkaline water is still used as the main source of edible protein upon drying. It has been expanded as protein supplement in many countries of Asia and produced industrially for human consumption. Certain perception is prevalent among the pregnant women that eating dihé cakes will guard their unborn baby from the eyes of magicians. Spirulina is also applied superficially as a poultice for treating certain diseases (Soni et al., 2017). Local trading value of the dihé annually harvested from Lake Kossorom in Chad amounts to more than US $\$ 100,000$, which signifies a critical impact to the economy of the area (Wan et al., 2016). Furthermore Spirulina has been suggested by European Space Agency and National Aeronautics for food supplementation during long-term space travels. Since then, there have been several animal and human clinical trials to determine its valuable effects as a supplement. Spirulina is a low-cost nutritional supplement and has not been recognized to have any noteworthy side effects. Spirulina is consumed as a sustaining food concentrate as it is very affluent in protein [60-70\%], vitamins [4\%], essential fatty acids and anti-oxidants (Santos, Freitas, Moreira, Zanfonato, \& Costa, 2016).

Spirulina is used as source of required fatty acids such as linoleic acid, linolenic acid, phycobiliproteins, the very important being phycocyanin and allophycocyanin, amino acids; the highest values are leucine $[10.9 \%$ of total amino acids], valine and isoleucine and minerals like iron. Groups of undernourished children and adults have reciprocated well to Spirulina administration. Treatment of the victims of nuclear disaster at Chernobyl, especially children whose bone marrow had been damaged from radiation exposure sustained the immune system. Toxicological research of all the Spirulina species have not exposed any toxic effect on kidney, liver, reproductive system and body physiology during and after acute or chronic doses. Spirulina does not contain cellulose cell walls and therefore does not require chemical or physical processes in order to become absorbable (Soni et al., 2017).

This study was aimed to observe the application of Spirulina as a food source with nutritional properties and evaluation of immunological applications, anti-cancer effects, probiotic property, neuroprotective property, hypoglycemic and hypolipidemic property, antinephrotoxicity, anti genotoxicity, antiviral activity, anti-inflammatory, anti-obesity and anti-cancer effects and their technological properties (Table 1).

\section{Spirulina as a wonderful future food source}

Spirulina has the wonderful ability to be used in preparing concentrated food of high quality. Nowadays Spirulina is a perfect food and nutritional supplement for the 21st century by the Food and Agriculture Organization (FAO) of the United Nations. The verification of food ingredients is of critical concern to food processors since the purity of food ingredients is certainly a subject to exploitation by unscrupulous suppliers (Rosario \& Josephine, 2015). Spirulina has been used as a complementary dietary ingredient of feed for fish, shrimp and poultry, and progressively as a protein and vitamin complement to aqua feeds. China is consuming of microalgae as a partial substitute of imported forage to motivate the growth, immunity and viability of shrimp. There has also been inclusive research on the use of Spirulina as aquaculture feed additives in Japan (Santos et al., 2016). Spirulina contains several nutrients and vitamins. It has all the essential amino acids, Beta carotene, Gamma linolenic acid, Vitamin B, trace elements, etc. It has $180 \%$ more calcium than milk, 5100\% more iron than spinach, $670 \%$ more protein than Tofu and $3100 \%$ more beta carotene than carrots. Three grams of Spirulina displays high antioxidant and anti-inflammatory activity than five more fruits and vegetables. In phytonutrients spirulina is 60 times better than spinach, 31 times better than blue berries and 700 times more potent than apples. It has numerous neutralizing and oxidative effects on free radicals and heavy metals (H.-L. Wu, Wang, Xiang, Li, \& $\mathrm{He}, 2016)$.

\section{Production of cookies enriched with Spirulina}

A cookie is an outstanding option among the products that can be enriched and mixed with Spirulina since it can be simply transported and has a long shelf life. Actually, using cyanobacteria as a nonconventional source of foods and protein seems to be hopeful. Donato et al., 2019, developed cookies mixed with $0,5,10$ and $15 \%$ of $S$. platensis for nutritional enrichment purposes. In the cookies, the increase of $S$. platensis percentage conducted to increment in protein percentage, compared with the cookie formed with only refined wheat flour. Cookies with $15 \%$ of $S$. platensis stood out regarding the percentages of minerals and protein and were similar to the whole cookies with respect to the lipids, minerals and maximum energetic value were observed in the standard cookies. Cookies mixed with 5\% of $S$. platensis and standard cookies were found to generate the same acceptability scores, demonstrating a remarkable response in the market (Donato et al., 2019).

\section{Usage of Spirulina platensis on soft cheese and ice cream}

Agustini et al., 2016, found the maximum concentration of $S$. platensis that can be added to the product and suitable based on sensory and physical properties. They displayed that addition of $1 \%$ and $1.2 \%$ S. platensis were used as the greatest concentration for soft cheese and ice cream, respectively. Addition of $S$. platensis gave significant effect to $\beta$ carotene, water, fat, protein, texture (soft cheese) and total sugar, overrun, melting point, total solid, fat and sensory (ice cream) (Winarni Agustini et al., 2016).

\section{Spirulina biscuit formulation with coconut cream}

Setyaningsih et al., 2019, evaluated the shelf life of the Spirulina biscuit and compared the chemical composition of Spirulina biscuit with the commercial biscuit. According to the sensory test, the Spirulina biscuit with coconut cream contains higher protein than a commercial biscuit, while it has lower lipid than that of the commercial biscuit. Moreover, evaluation of Spirulina biscuit shelf life stored at room temperature was 2.4 months (Setyaningsih, Mahmudah, Trilaksani, Tarman, \& Santoso, 2020).

\section{Spirulina as protein malnutrition}

Numerous studies on the chemical conformation of the biomass of S. platensis and S. maxima document remarkably high protein content. Such a high level of protein in Spirulina is uncommon even 

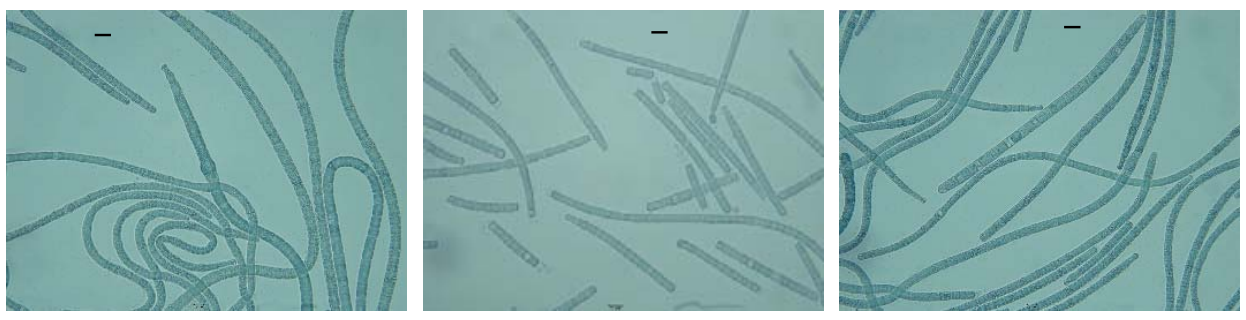

Figure 1| Photomicrograph of Spirulina sp. Bars, $10 \mu \mathrm{m}$.

Table 1| Bioactive properties of Spirulina

\begin{tabular}{|c|c|}
\hline Properties & Activity \\
\hline $\begin{array}{l}\text { As food supplement (in } \\
\text { cookies, ice cream and soft } \\
\text { cheese enriched with } \\
\text { Spirulina) }\end{array}$ & $\begin{array}{l}\text { Increases } \\
\text { - The protein content } \\
\text { - } \quad \text { The minerals } \\
\text { - } \quad \text { The phycobiliproteins } \\
\text { - } \quad \text { The fatty acids (myristic acid, palmitic acid, palmitoleic acid, Oleic acid, gamma linolenic acid) } \\
\text { - } \quad \text { The diversity of amino acids } \\
\text { - } \quad \text { The anti-oxidants activity } \\
\text { - } \quad \text { The vitamins } \\
\text { - The shelf-life }\end{array}$ \\
\hline Anti-nephrotoxicity & - $\quad$ Induced by Cisplatin, Cyclophosphamide, Cadmium and Chromium \\
\hline Anti-genotoxicity & $\begin{array}{ll}- & \text { Elevates the DNA repair procedure } \\
\text { - } & \text { Repairs process of cell nucleus enzymes } \\
\text { - } & \text { Protective effects against cyclophosphamide, cisplatin and urethane } \\
\text { - } \quad \text { Decreases the percentage of DNA fragmentation }\end{array}$ \\
\hline Antiviral activity & $\begin{array}{l}\text { - } \quad \text { Inhibitory activity against viruses such as HIV-1, HSV-1, HSV-2, HCMV and influenza type A, } \\
\text { - } \quad \text { Minimizes HIV-I replication }\end{array}$ \\
\hline Anti-inflammatory property & $\begin{array}{ll}- & \text { Lowers the extent of beta glucuronidase } \\
\text { - } & \text { Preserves against rheumatoid arthritis } \\
\text { - } & \text { Raises the activity of anti-oxidant enzyme }\end{array}$ \\
\hline $\begin{array}{l}\text { Anti-obesity and Weight } \\
\text { loss }\end{array}$ & $\begin{array}{ll}- & \text { Inhibits NADPH oxidase } \\
- & \text { Induces insulin resistance } \\
- & \text { Suppresses adipocyte oxidative stress }\end{array}$ \\
\hline $\begin{array}{l}\text { Hypoglycemic and } \\
\text { hypolipidemic property }\end{array}$ & $\begin{array}{ll}- & \text { Reduces the level of blood glucose } \\
- & \text { Manages cholesterol and triglycerides } \\
\text { - } & \text { Enhances insulin resistance }\end{array}$ \\
\hline Neuroprotective property & $\begin{array}{l}\text { - } \quad \text { Decreases the level of ROS, nitric oxide and lipid peroxidation } \\
\text { - } \quad \text { Improves locomotor activity }\end{array}$ \\
\hline Anti-cancer Effects & $\begin{array}{ll}- & \text { Enhances cell nucleus enzyme activity } \\
- & \text { Enhances DNA repair synthesis } \\
- & \text { Inhibits the growth of human colon carcinoma cells } \\
\text { - } & \text { Inhibits the hepatocellular carcinoma cells (HCC) } \\
- & \text { Inhibits the growth of breast cancer cells } \\
- & \text { Antiproliferative activity against the cancer cells } \\
- & \text { Inhibits the growth of liver cancer cells, hepatoma and lung cancer cells } \\
- & \text { Activates apoptosis enzymes }\end{array}$ \\
\hline Anti-anemic activity & $\begin{array}{ll}- & \text { Increases the concentration of mean capsular hemoglobin }(\mathrm{MCH}) \\
- & \text { Increases the mean concentration of haemoglobin } \\
- & \text { Increases mean corpuscular volume }(\mathrm{MCV}) \\
- & \text { Increases mean corpuscular hemoglobin }(\mathrm{MCH}) \\
- & \text { Increases mean corpuscular hemoglobin concentration }(\mathrm{MCHC})\end{array}$ \\
\hline Probiotic property & $\begin{array}{l}\text { - } \quad \text { Enhances the growth of Lactobacillus } \\
\text { - } \quad \text { Extension of vitamin } B_{1}\end{array}$ \\
\hline Spirulina for eyesight & $\begin{array}{ll}- & \text { Increases the serum zeaxanthin level } \\
\text { - } & \text { Inhibits the corneal neovascularization }\end{array}$ \\
\hline Immunological Applications & $\begin{array}{ll}- & \text { Improves anti-allergic effects } \\
\text { - } & \text { Inhibits the release of histamine }\end{array}$ \\
\hline
\end{tabular}


Table 2区 Vitamins and Minerals in Spirulina powder

\begin{tabular}{llll}
\hline Mineral & $\mathrm{mg} 100 \mathrm{~g}^{-1}$ & Vitamins & $\mathrm{mg} 100 \mathrm{~g}^{-1}$ \\
\hline Calcium & 700 & Provitamin A & $2.330 .000 \mathrm{IU} \mathrm{kg}^{-1}$ \\
\hline Chromium & 0.28 & ( 3 -carotene) & 140 \\
\hline Copper & 1.2 & Vitamin E & 100 a-tocopherol eq: \\
\hline Iron & 100 & Thiamin B1 & 3.5 \\
\hline Magnesium & 400 & Riboflavin B2 & 4 \\
\hline Manganese & 5 & Niacin B3 & 14 \\
\hline Phosphorus & 800 & Vitamin B6 & 0.8 \\
\hline Potassium & 1400 & Vitamin B12 & 0.32 \\
\hline Sodium & 900 & Folic acid & 0.01 \\
\hline & & Biotin & 0.01 \\
\cline { 2 - 4 } Zinc & 3 & Phantothenic acid & 0.1 \\
\cline { 2 - 4 } & & Vitamin K & 2.2 \\
\hline
\end{tabular}

in the microbial world, being surpassed only by certain bacteria like Cellulomonas, which is recorded to have protein levels above $80 \%$ of the dry weight (Kameshwari, Selvaraj, \& Sundaramoorthy, 2020).

However, this high protein content in those bacteria is accompanied by high nucleic acid content, which is medically undesirable. Additional nucleic acids result in uric acid accrual because of purine catabolism, which may in turn cause pathological situations such as gout. In Spirulina, the concentration of nucleic acid is always below $5 \%$ of the dry weight and is thus helpful. Research conducted on Spirulina by the World Health Organization (WHO) and scientists in the United States, France, West Germany, Mexico, Vietnam and Japan confirmed that it has a mixture of nutrients that no plant source can provide (Lupatini, Colla, Canan, \& Colla, 2017). The NPU value of Spirulina is equivalent to that of other vegetarian sources representing suitable amino acid composition, biological value and digestibility.

The amino acid profile of Spirulina protein is remarkable. Indeed, with the exception of cysteine and lysine, which are somewhat lower than that of the standard protein (FAO), all the other essential amino acids are present in adequate concentrations (Aiello et al., 2019). The potential use of Spirulina as a source of protein for human utilization has been widely recognized. Spirulina powder contains $65-70 \%$ of crude protein, whole powdered milk, soybean flour, Parmesan Cheese, Wheat germ, Peanuts, Chicken, Fish, and Beef meat, contain 37\%, $36 \%, 36 \%, 27 \%, 26 \%, 24 \%, 22 \%$ and $22 \%$ crude protein. Cphycocyanin is the significant phytochemical existing in the Spirulina which is rich in protein Spirulina contains eight necessary and eight non- necessary amino acids that build the protein molecule. Therefore it can be used as a main source for protein malnutrition (Benelhadj, Gharsallaoui, Degraeve, Attia, \& Ghorbel, 2016).

\section{Carbohydrates and Fatty acids of Spirulina}

The carbohydrates of Spirulina are easily digested owing to the absence of cellulose. Further, the absence of free sugars, makes it an ideal food supplement for diabetes, obesity and such other conditions (Braga, Mastrantonio, Costa, \& Morais, 2018).
Spirulina has yet another merit in its lipid composition, being cholesterol free and rich in poly-unsaturated essential fatty acids, which is suitable for conditions like atherosclerosis, obesity and blood pressure. Additionally, Spirulina is rich in myristic acid (0.23\%), palmitic acid (46.07), palmitoleic acid (1.26), Oleic acid (5.26), gamma

linolenic acid (17.43\%), and thus has medical implications (T.-T. Li et al., 2019).

Since 1981, Spirulina has been found to have lipid lessening abilities. Later in 1990, Iwata et al evaluated the preclinical trial on Wistar rats, which were artificially induced with hyperlipidemia by nourishing a high-fructose diet. The groups were either on high fructose diet alone or on a high-fructose diet with Spirulina at 5\%, 10\%, and $15 \%$ concentrations for 4 weeks. The results discovered a significant enhancement in the lipid profile with increased activity of lipoprotein lipase (LPL), however, the difference in lipid levels or LPL was not significantly different between $5 \%, 10 \%$, or $15 \%$ Spirulina

concentration groups. Moreover, they showed that with the administration of $5 \%$ spirulina, hepatic triacylglycerols decreased (Iwata, Inayama, \& Kato, 1990). Similar to other previous studies, it was also shown that consumption of Spirulina for eight weeks increased HDL-C and lowered LDL-C, TG, and TC levels when fed a high-fat diet. Moreover, Spirulina consumption could significantly normalize hepatic steatosis with improvements in liver function tests, including transaminases, free fatty acids, and overall lipid profile. This achievement was supposed to be secondary to activation of AMPactivated protein kinase signaling pathway which consequently downregulates the expression of lipid synthesizing genes, specially sterol regulatory element-binding transcription factor-1c, 3-hydroxy- 3methyl glutaryl coenzyme A reductase, and acetyl CoA carboxylase which ultimately reduce TG levels and successfully inhibit the synthesis of fatty acids (T.-T. Li et al., 2018).

\section{Vitamins and minerals of Spirulina}


Spirulina has an excellent blend of vitamins, including Vitamins A, $\mathrm{B}_{1}, \mathrm{~B}_{2}, \mathrm{~B}_{6}, \mathrm{~B}_{12}$, E and $\mathrm{H}$. It contains $21 \%$ of the Recommended Dietary Allowance (RDA) in the case of thiamin and riboflavin (Nowruzi, Haghighat, Fahimi, \& Mohammadi, 2018). It has a B-carotene content, which is 20 times higher than that of carrots. Its folic acid and vitamin $\mathrm{B}_{12}$ contents make it a good therapeutic food for anemia. The mineral make-up of Spirulina is attractive too. It has 12 times higher levels of iron than that of any other food and is also rich in magnesium, potassium and other trace elements. Spirulina being chiefly rich in calcium and iron is good for blood rejuvenation and healthy working of teeth and bones. The nutritional worth of Spirulina has been well documented by complete studies carried out by UNIDO; Central Food Technological Research Institute, Mysore and several international agencies (Grosshagauer, Kraemer, \& Somoza, 2020).

Spirulina comprises critical minerals and trace elements absorbed from its growth medium into chelated, simply absorbed forms are potassium, a vital mineral that controls body electrolyte equilibrium. Iron scarcity is greatest common among women in their generative years. Iron in some nutritional complements is not appropriately absorbed, however in Spirulina is better absorbed than ferrous sulfate and other supplements. Subsequently, it could signify a suitable source of iron in anemic pregnant women (Table 2) (Andrade, 2018).

\section{Anti-nephrotoxicity and Anti genotoxicity of Spirulina}

Spirulina decreases the urea and creatinine level in rats with nephrotoxicity persuaded by cisplatin. Moreover Spirulina give protection against nephrotoxicity and neurotoxicity in rats induced by cyclophosphamide, cadmium induced toxicity in albino rats and renal toxicity in wistar rats, chromium induced nephrotoxicity in rats (Abdel-Daim et al., 2019).

Polysaccharides of Spirulina conserve DNA barren to radiation from being destroyed chiefly the action of excision repair and configuration of unintended Spirulina also expressed to reduce the recurrence of micronucleus in polychromatic erythrocytes of bone mice unprotected to gamma radiation. Moreover, polysaccharide of Spirulina initiates the repair process of cell nucleus enzymes and elevate the DNA repair procedure. On the contrary, Spirulina was found to be protective toward mice from unpleasant effects of few toxicants like cyclophosphamide, cisplatin and urethane by condensing both lipid peroxidation and chromosomal construction. Spirulina significantly lowered the percentage of DNA fragmentation in liver and decreasing the occurrence of micronucleus in erythrocytes of animal fed diet abomination with aflatoxin (Aly, Kotb, \& Hammad, 2018).

\section{Antiviral activity of Spirulina}

Spirulina has all bioactive compounds in its constitution that can build a healthy immune system, which scavenges free radicals as well. Bioactive compounds extracted from Spirulina have inhibitory activity against an extensive variety of viruses such as HIV-1, HSV-1, HSV-2, HCMV, influenza type A, measles, etc. Spirulina platensis was shown to reduce HIV-I duplication in human T-cell lines, peripheral blood mononuclear cells and Langerhans cells (Nowruzi, Sarvari, \& Blanco, 2020a). The most likely antiviral components of Spirulina are the protein phycocyanin, sulphated polysaccharide fragments, GLA and some sulpholipids. Sulphated polysaccharide of Spirulina ejects its antiviral activity by suppressing the replication of human cytomegalovirus, herpes simplex, human immunodeficiency, influenza A, mumps, measles and white spot syndrome viruses. The effective concentration of calcium in spirulina decrease viral multiplication by $50 \%$. It is also called that Spirulina strains have 2-5\% of sulpholipids, which are helpful against human immunodeficiency virus, particularly dealing against DNA polymerase for 50\% inhibition of the virus. Allophycocyanin extracted from Spirulina platensis, has revealed an antiviral act against enterovirus 71 (Abd El-Baky \& ElBaroty, 2020).

\section{Anti-inflammatory property of Spirulina}

Spirulina displays anti-inflammatory effect averse to Zymosan producing arthritis in mice by decreasing the amount of beta glucurnidase in the diarthrosis fluid. Ethanolic extract of Spirulina platensis keeps significant anti-inflammatory activity in both carrageenan induced raw paw edema test. Spirulina could control the undesirable effects of acetic acid persuaded ulcerative colitis in rats demonstrated by raising the activity of anti-oxidant enzyme CAT and SOD in addition to GSH content with, considerable depletion in lipid peroxidation makes MDA and protein carbonyl inclusion to control prostaglandins as well as pro inflammatory cytokines (Nowruzi, Sarvari, \& Blanco, 2020b; Q. Wu et al., 2016).

\section{Anti-obesity and Weight loss of Spirulina}

According to the 2016 global health report, more than 1.9 billion adults were categorized as overweight; 650 million among them being obese. Totally, around 2.8 million adults are assessed to die every year from it. Obesity has been carefully linked to inflammation, hyperlipidaemia and insulin resistance. This may be due to the fact that adipose tissue secretes several biologically active substances like adipokines and chemokines, which play a significant role in inflammation and the development of atherosclerosis (DiNicolantonio, Bhat, \& OKeefe, 2020). While caloric restriction and exercise are the mainstay treatments for obesity, Spirulina has revealed noteworthy benefits in helping weight loss. The phycocyanin in Spirulina is capable of inhibiting NADPH oxidase, a substantial source of oxidative stress in adipocytes playing a main role in shifting adipokine and cytokine production in hypertrophied adipocytes and inducing insulin resistance. Thus, by suppressing adipocyte oxidative stress, Spirulina may cause systemic anti-inflammatory and insulinsensitizing effects.

Several clinical and preclinical trials have been shown to test the advantage of Spirulina on weight loss (DiNicolantonio et al., 2020). Yousefi et al studied 52 obese participants with a body mass index (BMI) $>25-40 \mathrm{~kg} / \mathrm{m} 2$ who were randomized to $2 \mathrm{~g}$ Spirulina per day with a restricted caloric diet. Participants in the Spirulina group had significantly lower body weight (Yousefi, Mottaghi, \& Saidpour, 2018). Zeinalian et al studied 62 obese subjects after administering $1 \mathrm{~g}$ Spirulina and observed a significant reduction in appetite by $4.16 \%$ and a reduction in total cholesterol by $4.67 \%$ (Zeinalian, Farhangi, Shariat, \& Saghafi-Asl, 2017). Additionally, high density lipoproteincholesterol was noted to increase by $1.73 \%$ with no significant change in TG or low density lipoprotein. Several tests have also used Spirulina maxima to assess its beneficial effects. Spirulina maxima in 40 
hypertensive patients were documented without sign of cardiovascular disease when supplemented with $2 \mathrm{~g}$ of Spirulina per day versus placebo for 3 months (DiNicolantonio et al., 2020).

\section{Hypoglycemic and hypolipidemic property of Spirulina}

Spirulina maxima had a significant role in covering mice from hyperlipidemic collected by simvastatin by lessening the contents of total lipid and triacylglycerols. Spirulina also shows anti-lipidemic and anti-hyperglycemia activity by reducing the level of blood glucose, managing cholesterol and triglycerides and enhancing insulin resistance (El-Sayed, Hikal, Abo El- Khair, El-Ghobashy, \& El-Assar, 2018).

Spirulina maxima reacts as hypoglycemic factor in streptozotocin persuaded diabetic male wistar rats. The Hypocholestrolemic and hyperglycemic effect of Spirulina is related to obesity and aging in rats where oral regulation of Spirulina united with glycyrrhizin to rats lowered the serum glucose, cholesterol and leptin level as well as the acetyl cholinesterase activity in the hippocampal tissue homogenates of the obese rats.

Spirulina also has neuroprotective capability where it significantly decreased the amount of violation of cerebral cortex and raised post stroke locomotor activity in rats. Executive of Spirulina for long duration could reduce the ischemic brain destruction as well as displayed a defensive role in nervous system against oxidative strain initiated by disclosure to fluoride in the progeny of pregnant rats naked to fluoride (El-Sayed et al., 2018).

\section{Neuroprotective property of Spirulina}

Spirulina maxima shows neuroprotective effect against the 6hydroxydopamine (6-OHDA)-induced toxicity in the rat striatum and found that spirulina maxima decreased the level of ROS, nitric oxide and lipid peroxidation in the striatum with developed locomotor activity with conservation of dopamine mitochondrial activity. Likewise, care of rats with Spirulina platensis had some favorable effect in intensifying the locomotor function of hind limb and diminish the morphological injury of the spinal cord (Sinha, Patro, \& Patro, 2018).

\section{Anti-cancer effects}

Some studies have shown that Spirulina extract can prevent or inhibit cancers in animals and humans. In vitro assessment proposes that polysaccharides of Spirulina improve cell nucleus enzyme activity and DNA repair synthesis. The water extract of Spirulina platensis inhibited the growth of human colon carcinoma cells and hepatocellular carcinoma cells (HCC) in in vitro studies. The chloroform extract of crude Spirulina platensis and Chlorella vulgaris inhibited the viability of breast cancer cells in vitro (Ramakrishnan, 2013). In fact, it has the antiproliferative activity against the cancer cells. The methanolic extract of the Spirulina inhibited the growth of human breast cancer cell line and the human cancer cell line L20B within short incubation period. The extract of $S$. platensis also prevents the growth of mice intestinal carcinoma cell lines. The $70 \%$ ethanolic extract of Spirulina shows considerable effect of cytotoxicity in human acute leukemia kasumi - 1 and chronic myelogenous leukemia k - 562 cell lines. Other than these cancerous cells the Spirulina extract inhibit the growth of liver cancer cells, hepatoma and lung cancer cells in mice, oral squamous cell carcinoma in human and hamster, squamous cell carcinoma and oral buccal pouches tumor in hamster (Ramakrishnan, 2013).

One of the most well-known important natural anti-cancer substances is beta carotene. Studies associated to use of beta carotene on animals represented that a smaller but statistically major reduction in tumor number and size. The polysaccharides isolated from Spirulina improved both the repair activity of radiation damaged. The polysaccharides isolated from Spirulina platensis extract inhibited DNA synthesis of sarcoma 180 and ascetic hepatoma cells and inhibited the proliferation of ascites hepatoma cells of mice. Calcium spirulina is a polysaccharide of Spirulina platensis inhibited tumor attack and metastasis caused reduction of lung tumor colonization of B16-BL6 cells in a spontaneous lung metastasis model. The suppression of glioma cell growth by complex polysaccharides from Spirulina occurs via partial regulation of interleukin-17 production and down regulation of angiogenesis (Kawanishi et al., 2013). The selenium nanoparticles with Spirulina polysaccharides named SPSSeNPs may be a potential candidate against human cancers as a chemopreventive and chemotherapeutic agent (Chen et al., 2012).

Oral administration of phycocyanin cause increase in the survival rate of mice with live tumor cells. Moreover the phycocyanin isolated from Spirulina platensis showed anticancer activity against squamous cell carcinoma. From Schwartz and Shklar (1987) studies detected that the regression of tumor induced by DMBA (7,12 dimethylbenz(a)anthracene) persuaded squamous cell carcinoma in hamster. The oral administration of Spirulina and Dunaliella extract banned tumor development in hamster, due to immune response Spirulina extract blocks cancer expansion and finishes developing malignant cells. Moreover, Schwartz and Shklar (1987) found that Spirulina and Dunaliella extract are not toxic to normal cells (Schwartz \& Shklar, 1987). The inhibition of growth and cell viability of human leukemia K562 cells by C-phycocyanin (C-PC) isolated from Spirulina platensis and due to involvement of different types of mechanisms ( $\mathrm{Liu}, \mathrm{Xu}$, Cheng, Lin, \& Zhang, 2000).

C- phycocyanin (C-PC) is a most important biliproteins of Spirulina platensis has antioxidant activity and radical scavenging. C$\mathrm{PC}$ is an inhibitor of cycloxinase - 2, induces apoptosis (in vitro) and exhibits anti-inflammatory and anti-cancer properties (Reddy et al., 2003). The increased phycocyanin of $S$. platensis induces apoptosis by the expression of CD59 proteins in HeLa cells (B. Li, Zhang, Gao, \& $\mathrm{Chu}, 2005)$. The C-PC prompts apoptosis in HeLa cells by activating apoptosis enzymes, caspases 2, 3, 4, 6, 8, 9, and caspase - 10. In fact, it induces release of cytochrome $c$ from the mitochondria into the cytosol that was related to apoptosis of C-PC-treated HeLa cells (B. Li et al., 2005). The PC of Spirulina platensis has possible cancer chemopreventive property. The selenium-containing phycocyanin (Se-PC) from Spirulina platensis was recognized as a strong antiproliferative factor on human melanoma A375 cells and human breast adenocarcinoma MCF-7 cells. The Se-PC persuades apoptosis by accretion of sub-G1 cells, and nuclear condensation, DNA fragmentation in both MCF- 7 and A375 cells (Chen \& Wong, 2008).

\section{Anti-anemic activity}

The constant supplementation of Spirulina to the old people with anemia increases the concentration of mean capsular hemoglobin 
$(\mathrm{MCH})$ in blood. Moreover, 12 weeks supplementation of Spirulina shows significant increase in the mean concentration of haemoglobin, mean corpuscular volume (MCV), mean corpuscular hemoglobin $(\mathrm{MCH})$ and mean corpuscular hemoglobin concentration (MCHC) in the children with anemia and it increases the level of iron in blood, thus the Spirulina can be used as medicine for anemia (Mani, Sadliwala, Iyer, \& Parikh, 2000).

\section{Probiotic property of Spirulina}

Spirulina reacts as a usable food sustaining favorable intestinal flora. Nourishing rats, a diet addition with 5\% Spirulina for 100 days resulted in extension of Lactobacillus by $32.7 \%$ and extension of vitamin $\mathrm{B}_{1}$. Moreover, extracellular products produced by Spirulina platensis significantly increased the growth of lactic acid bacteria such as Lactococcus lactis, Streptococcus thermophilus, Lactobacillus casei, Lactobacillus acidophilus, and Lactobacillus bulgaricus (Golmakani, Soleimanian-Zad, Alavi, Nazari, \& Eskandari, 2019).

\section{Spirulina for eyesight}

Spirulina is rich in zeaxanthin, a xanthophyll that exists in human eyes, which decreases the chance of cataracts and age related macular degeneration. Dried Spirulina powder contains $74000 \mu \mathrm{g}$ of zeaxanthin and dietary supplement of Spirulina powder increases the serum zeaxanthin level in human. Relevant function of the extract of Spirulina platensis inhibit the corneal neovascularization induced by $\mathrm{NaOH}$ in mice (Kameshwari et al., 2020).

\section{Immunological Applications}

Spirulina became well known by NASA as a nutritional complement for astronauts on space missionary, it repressed the release of histamine by mast cells, and Spirulina may expand numerous symptoms of anti-allergic effects. Spirulina has no effect on chronic fatigue. Spirulina extract plus zinc may be valued for the treatment of chronic arsenic poisoning with melanosis and keratosis. The first human feeding study proved the defensive effects of Spirulina towards allergic rhinitis. Spirulina helps to defend against certain nutritional deficits (Ghattas, Dawoud, Mahrous, \& Elgabry, 2019). It theatres in the inhibition of cancer, infectious diseases, cellular ageing and reduced immune system efficiency as well as play a significant role in the working of the medulla. Extract of Spirulina, has a defensive effect against apoptotic cell death due to free radicals. Spirulina was a stronger inhibitor than Chlorella. Annexin-V staining presented that extract of Spirulina persuaded apoptosis of hepatic stellate cell (HSC) after $12 \mathrm{~h}$ of treatment. Furthermore, the extract of Spirulina activated a cell cycle arrest of HSC at the G2/M phase. Spirulina platensis enhances the immune response by activating macrophage functions, IL - I production, phagocytosis and particularly by primary response (Chia et al., 2019).

\section{Global Spirulina Market}

Spirulina is advertised and consumed in several different countries such as Belgium, Egypt, United States, Germany, Ireland, Argentina, Philippines, India, Brazil, Chile, Spain, France, Canada, Africa, and other countries, where public management and associations have approved human consumption. Some of the greatest universal wellknown Spirulina creating companies are: Cyanotech (USA), Hainan
DIC Microalgae Co., Ltd (China), Earthrise Farms (USA), Marugappa Chettir Research Center (India), Genix (Cuba) and Solarium Biotechnology (Chile) (Costa et al., 2019).

\section{Future research and perspective views}

Biodiesel and nutraceutical production from Spirulina strains, although requires further research, can achieve commercial success by development of advanced culture techniques by mimicking the natural conditions have immense potential to improvement activities such as fast-growing and high lipid-secreting ability. In fact, now various strains of Spirulina were identified, isolated, cultured, and characterized using molecular techniques, biochemical, nutraceutical and the isolation stage being the starting point to achieve various biotechnological applications.

Moreover Spirulina strains could be used for developing new therapeutics against novel viruses, such as coronavirus (SARS-CoV-2). However, additional research requests to emphasis on the satisfactory axenic culturing of Spirulina in order to simplify their exploitation for bioactive compounds. The present and future trends in the research of Spirulina strains include integrated multi-omics analysis for detection of biosynthetic gene clusters, biosynthetic pathways, and metabolic engineering for enhanced production of target compounds. The metabolomics analysis of field-collected materials by using the tool as LC-TOF-ESI-MS/MS, HR-ESI-MS, MALDI-TOF-MS, etc., are assisting the de-replication of the known compounds, and search for novel molecules.

\section{Conclusion}

The present review concludes that the Spirulina is used as a potential health food in human diet and used in food industry. It is a super food and a best dietary source for the malnutrition. It lowers cholesterol, suppresses fatty accumulation in the liver, prevents tumor formation, enhances the immune system and protects kidneys. $S$. platensis are known to contain an excellent source of minerals, especially calcium and potassium, proteins, carbohydrates, essential fatty acids, vitamins, minerals, carotenes, chlorophyll $a$ and phycocyanin. Therefore Spirulina could be used as medicine for diseases as well as daily nutrient source.

\section{Author Contribution}

BN supervised and proof-read the manuscript. AAA prepared the manuscript.

\section{Acknowledgment}

NA

\section{Competing financial interests}

Authors have declared that no competing interest exists.

\section{References}

Abd El-Baky, H. H., \& El-Baroty, G. S. (2020). Spirulina maxima L-asparaginase: Immobilization, Antiviral and Antiproliferation Activities. Recent Patents on Biotechnology, 14(2), 154163. https://doi.org/10.2174/1872208313666191114151344

Abdel-Daim, M. M., Ahmed, A., Ijaz, H., Abushouk, A. I., Ahmed, H., Negida, A., ... Bungau, S. G. (2019). Influence of Spirulina platensis and ascorbic acid on amikacin-induced 
nephrotoxicity in rabbits. Environmental Science and Pollution Research, 268), 80808086. https://doi.org/10.1007/s11356-019-04249-4

Aiello, G., Li, Y., Boschin, G., Bollati, C., Arnoldi, A., \& Lammi, C. (2019). Chemical and biological characterization of spirulina protein hydrolysates: Focus on ACE and DPP-IV activities modulation. Journal of Functional Foods, 63, 103592. https://doi.org/10.1016/j.jff.2019.103592

Ali, S. K., \& Saleh, A. M. (2012). Spirulina - An overview. International Journal of Pharmacy and Pharmaceutical Sciences. https://doi.org/10.1201/9780203025901.ch14

Aly, F. M., Kotb, A. M., \& Hammad, S. (2018). Effects of Spirulina platensis on DNA damage and chromosomal aberration against cadmium chloride-induced genotoxicity in rats. Environmental Science and Pollution Research, 25(11), 10829-10836. https://doi.org/10.1007/s11356-018-1329-3

Andrade, L. M. (2018). Chlorella and Spirulina Microalgae as Sources of Functional Foods, Nutraceuticals, and Food Supplements; an Overview. MOJ Food Processing \& Technology, 61). https://doi.org/10.15406/mojfpt.2018.06.00144

Benelhadj, S., Gharsallaoui, A., Degraeve, P., Attia, H., \& Ghorbel, D. (2016). Effect of pH on the functional properties of Arthrospira (Spirulina) platensis protein isolate. Food Chemistry, 194, 1056-1063. https://doi.org/10.1016/j.foodchem.2015.08.133

Braga, V. da S., Mastrantonio, D. J. da S., Costa, J. A. V., \& Morais, M. G. de. (2018). Cultivation strategy to stimulate high carbohydrate content in Spirulina biomass. Bioresource Technology, 269, 221-226. https://doi.org/10.1016/j.biortech.2018.08.105

Chen, T., \& Wong, Y.-S. (2008). In Vitro Antioxidant and Antiproliferative Activities of SeleniumContaining Phycocyanin from Selenium-Enriched Spirulina platensis. Journal of Agricultural and Food Chemistry, 5612), 4352-4358. https://doi.org/10.1021/jf073399k

Chen, T., Yang, Tang, Zhong, Bai, Zhang, ... Zheng. (2012). Surface decoration by Spirulina polysaccharide enhances the cellular uptake and anticancer efficacy of selenium nanoparticles. International Journal of Nanomedicine, 835. https://doi.org/10.2147/IJN.S28278

Chia, S. R., Chew, K. W., Show, P. L., Xia, A., Ho, S.-H., \& Lim, J. W. (2019). Spirulina platensis based biorefinery for the production of value-added products for food and pharmaceutical

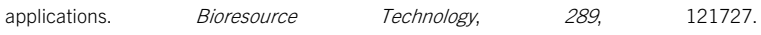
https://doi.org/10.1016/j.biortech.2019.121727

Costa, J. A. V., Freitas, B. C. B., Rosa, G. M., Moraes, L., Morais, M. G., \& Mitchell, B. G. (2019). Operational and economic aspects of Spirulina-based biorefinery. Bioresource Technology, 292, 121946. https://doi.org/10.1016/j.biortech.2019.121946

DiNicolantonio, J. J., Bhat, A. G., \& OKeefe, J. (2020). Effects of Spirulina on weight loss and blood lipids: a review. Open Heart, 71 ), e001003. https://doi.org/10.1136/openhrt-2018001003

Donato, N. R., Queiroz, A. J. D. M., Feitosa de Figueirêdo, R. M., Feitosa, R. M., Moreira, I. D. S., \& Lima, J. F. de. (2019). Production of Cookies Enriched With Spirulina platensis Biomass. Journal of Agricultural Studies, ᄌ2), 323. https://doi.org/10.5296/jas.v7i4.15483

El-Sayed, E.-S., Hikal, M., Abo El- Khair, B., El-Ghobashy, R., \& El-Assar, A. (2018). Hypoglycemic and Hypolipidemic Effects of Spirulina Platensis, Phycocyanin, Phycocyanopeptide and Phycocyanobilin on Male Diabetic Rats. Arab Universities Journal of Agricultural Sciences, 26(3), 1121-1134. https://doi.org/10.21608/ajs.2018.28365

Ghattas, T. A., Dawoud, E. N., Mahrous, A. F., \& Elgabry, E. A. (2019). Effect of Spirulina platensis supplementation on growth, some biochemical and immunological parameters in suckling calves. Egyptian Veterinary Medical Association, 79, 443-460.

Golmakani, M.-T., Soleimanian-Zad, S., Alavi, N., Nazari, E., \& Eskandari, M. H. (2019). Effect of
Spirulina (Arthrospira platensis) powder on probiotic bacteriologically acidified feta-type cheese. Journal of Applied Phycology, 31(2), 1085-1094. https://doi.org/10.1007/s10811-018-1611-2

Grosshagauer, S., Kraemer, K., \& Somoza, V. (2020). The True Value of Spirulina. Journal of Agricultural and Food Chemistry, 68(14), 4109-4115. https://doi.org/10.1021/acs.jafc.9b08251

Iwata, K., Inayama, T., \& Kato, T. (1990). Effects of Spirulina platensis on plasma lipoprotein lipase activity in fructose-induced hyperlipidemic rats. Journal of Nutritional Science and Vitaminology, 36(2), 165-171. https://doi.org/10.3177/jnsv.36.165

Kameshwari, V., Selvaraj, S., \& Sundaramoorthy, S. (2020). Single Cell Protein Spirulina-A Nutrient Treasure. Research Journal of Pharmacology and Pharmacodynamics, 12(2), 49. https://doi.org/10.5958/2321-5836.2020.00010.5

Kawanishi, Y., Tominaga, A., Okuyama, H., Fukuoka, S., Taguchi, T., Kusumoto, Y., ... Shimizu, K. (2013). Regulatory effects of Spirulina complex polysaccharides on growth of murine RSVM glioma cells through Toll-like receptor 4. Microbiology and Immunology, 5ג1), 63-73. https://doi.org/10.1111/1348-0421.12001

Li, B., Zhang, X., Gao, M., \& Chu, X. (2005). Effects of CD59 on antitumoral activities of phycocyanin from Spirulina platensis. Biomedicine \& Pharmacotherapy, 5910), 551-560. https://doi.org/10.1016/j.biopha.2005.06.012

Li, T.-T., Liu, Y.-Y., Wan, X.-Z., Huang, Z.-R., Liu, B., \& Zhao, C. (2018). Regulatory Efficacy of the Polyunsaturated Fatty Acids from Microalgae Spirulina platensis on Lipid Metabolism and Gut Microbiota in High-Fat Diet Rats. International Journal of Molecular Sciences, 1910), 3075. https://doi.org/10.3390/ijms19103075

Li, T.-T., Tong, A.-J., Liu, Y.-Y., Huang, Z.-R., Wan, X.-Z., Pan, Y.-Y., ... Zhao, C. (2019). Polyunsaturated fatty acids from microalgae Spirulina platensis modulates lipid metabolism disorders and gut microbiota in high-fat diet rats. Food and Chemical Toxicology, 131, 110558. https://doi.org/10.1016/j.fct.2019.06.005

Liu, Y., Xu, L., Cheng, N., Lin, L., \& Zhang, C. (2000). Inhibitory effect of phycocyanin from Spirulina platensis on the growth of human leukemia K562 cells. Journal of Applied Phycology. https://doi.org/10.1023/A:1008132210772

Lupatini, A. L., Colla, L. M., Canan, C., \& Colla, E. (2017). Potential application of microalga Spirulina platensis as a protein source. Journal of the Science of Food and Agriculture, 973), 724732. https://doi.org/10.1002/jsfa.7987

Mani, U., Sadliwala, A., lyer, U., \& Parikh, P. (2000). The Effect of Spirulina Supplementation on Blood Haemoglobin Levels of Anaemic Adult Girls. Journal of Food Science and Technology.

Nowruzi, B., Haghighat, S., Fahimi, H., \& Mohammadi, E. (2018). Nostoc cyanobacteria species: a new and rich source of novel bioactive compounds with pharmaceutical potential. Journal of Pharmaceutical Health Services Research, 91), 5-12. https://doi.org/10.1111/jphs.12202

Nowruzi, B., Sarvari, G., \& Blanco, S. (2020a). Applications of cyanobacteria in biomedicine. In Handbook of Algal Science, Technology and Medicine (pp. 441-453). Elsevier. https://doi.org/10.1016/B978-0-12-818305-2.00028-0

Nowruzi, B., Sarvari, G., \& Blanco, S. (2020b). The cosmetic application of cyanobacterial secondary metabolites. Algal Research, 49, 101959. https://doi.org/10.1016/..algal.2020.101959

Ramakrishnan, R. (2013). Anticancer properties of blue green algae Spirulina platensis - A Review. International Journal of Medicine and Pharmaceutical Sciences (IJMPS).

Reddy, M. C., Subhashini, J., Mahipal, S. V. ., Bhat, V. B., Srinivas Reddy, P., Kiranmai, G., ... 
Reddanna, P. (2003). C-Phycocyanin, a selective cyclooxygenase-2 inhibitor, induces apoptosis in lipopolysaccharide-stimulated RAW 264.7 macrophages. Biochemical and Biophysical Research Communications, 304(2), 385-392. https://doi.org/10.1016/S0006-291X(03)00586-2

Rosario, J. C., \& Josephine, R. M. (2015). Mineral profile of edible algae Spirulina platensis. Int J Curr Microbiol App Sci, 4(1), 478-483.

Santos, T. D., Freitas, B. C. B. de, Moreira, J. B., Zanfonato, K., \& Costa, J. A. V. (2016). Development of powdered food with the addition of Spirulina for food supplementation of the elderly population. Innovative Food Science \& Emerging Technologies, 37, 216-220. https://doi.org/10.1016/j.ifset.2016.07.016

Schwartz, J., \& Shklar, G. (1987). Regression of experimental hamster cancer by beta carotene and algae extracts. Journal of Oral and Maxillofacial Surgery, 45(6), 510-515. https://doi.org/10.1016/S0278-2391(87)80011-3

Setyaningsih, I., Mahmudah, P., Trilaksani, W., Tarman, K., \& Santoso, J. (2020). Spirulina biscuit formulation with coconut cream substitution and its shelf life estimation. IOP Conference Series: Earth and Environmental Science, 414, 012022. https://doi.org/10.1088/17551315/414/1/012022

Sinha, S., Patro, N., \& Patro, I. K. (2018). Maternal Protein Malnutrition: Current and Future Perspectives of Spirulina Supplementation in Neuroprotection. Frontiers in Neuroscience, 12. https://doi.org/10.3389/fnins.2018.00966

Soni, R. A., Sudhakar, K., \& Rana, R. S. (2017). Spirulina - From growth to nutritional product: A review. Trends in Food Science \& Technology, 69, 157-171. https://doi.org/10.1016/j.tifs.2017.09.010

Wan, D., Wu, Q., \& Kuča, K. (2016). Spirulina. In Nutraceuticals (pp. 569-583). Cambridge, MA, USA: Academic Press.

Winarni Agustini, T., Farid Ma'ruf, W., Widayat, W., Suzery, M., Hadiyanto, H., \& Benjakul, S. (2016). Application of Spirulina platensis on Ice Cream and Soft Cheese with Respect to Their Nutritional and Sensory Perspectives. Jurnal Teknologi, 78(4-2). https://doi.org/10.11113/jt.v78.8216

Wu, H.-L., Wang, G.-H., Xiang, W.-Z., Li, T., \& He, H. (2016). Stability and Antioxidant Activity of Food-Grade Phycocyanin Isolated from Spirulina platensis. International Journal of Food Properties, 1910), 2349-2362. https://doi.org/10.1080/10942912.2015.1038564

Wu, Q., Liu, L., Miron, A., Klímová, B., Wan, D., \& Kuča, K. (2016). The antioxidant, immunomodulatory, and anti-inflammatory activities of Spirulina: an overview. Archives of Toxicology, 908), 1817-1840. https://doi.org/10.1007/s00204-016-1744-5

Yousefi, R., Mottaghi, A., \& Saidpour, A. (2018). Spirulina platensis effectively ameliorates anthropometric measurements and obesity-related metabolic disorders in obese or overweight healthy individuals: A randomized controlled trial. Complementary Therapies in Medicine, 40, 106-112. https://doi.org/10.1016/j.ctim.2018.08.003

Zeinalian, R., Farhangi, M. A., Shariat, A., \& Saghafi-Asl, M. (2017). The effects of Spirulina Platensis on anthropometric indices, appetite, lipid profile and serum vascular endothelial growth factor (VEGF) in obese individuals: a randomized double blinded placebo controlled trial. BMC Complementary and Alternative Medicine, 1オ1), 225. https://doi.org/10.1186/s12906-017-1670-y
Submit your next manuscript to Microbial Bioactives published by EMAN Research

- Convenient online submission

- Thorough peer review

- No space constraints or color figure charges

- Immediate publication on acceptance

- Inclusion in Australian National Libraray and Google Scholar

- $\quad$ Both Open (80-100\% subsidized APC by ER) \& non-open access option Submit your manuscript at

https://microbialbioactives.emanresearch.org 